\title{
Lo sensorial, la apreciación y el coleccionismo: La Vista y el ima- ginario en la Corte de Felipe IV
}

\author{
The sensorial, the appreciation and the collecting: The Sense of Sight and the \\ imaginary at the Court of Philip IV
}

\author{
Paulina Ocampo Martínez \\ Facultad de Filosofía y Letras, Universidad Nacional Autónoma de México. \\ pau.unam.99@outlook.com
}

Fecha de recepción: 15 de agosto de 2019

Fecha de aprobación: 20 de diciembre de 2019

\begin{abstract}
Resumen
Las siguientes páginas versan sobre cómo el cuadro La Vista de Jan Brueghel y Pedro Pablo Rubens contribuye en la consolidación de un imaginario en la corte de Felipe IV, en un momento de crisis, pero en el que las artes tuvieron un gran desarrollo y crecimiento y en el que el poder del monarca era reforzado a través de imágenes, símbolos y ceremonias. Asimismo, la legitimación del poder del rey estaba vinculada con diversas prácticas culturales de Europa durante la primera mitad del siglo XVII.
\end{abstract}

Palabras clave: Imaginario, imágenes, legitimación del poder, prácticas culturales europeas.

\begin{abstract}
The next pages discuss how the painting The Sense of Sight by Jan Brueghel and Peter Paul Rubens helped to consolidate an imaginary at the Court of Philip IV, during a crisis moment, but in a time in which the arts had a great development and growth. Also it was in that moment when the king's power was strengthened through images, symbols and ceremonies. Likewise, the legitimation of king's power was linked up with diverse cultural European practices in the first half of the seventeenth century.
\end{abstract}

Keywords: Imaginary, images, legitimation of the power, cultural European practices. 
Y lo cierto es, que nunca luzen tanto la una ni la otra, como quando juntas se dan las manos, y concurren con su valentía y hermosura, en los retablos de las Iglesias, en las galerías y camarines ${ }^{1}$.

Aunque la Pintura se lleva la gala de la hermosura; dixo Homero (hablando de la nobleza y la hermosura) que ambas agradavan, la nobleza al entendimiento, y la hermosura a los sentidos ${ }^{2}$.

Vicente Carducho, Diálogos de la pintura. Su defensa, origen, esencia, definición, modos y diferencias.

Entre 1617 y 1618, Jan Brueghel y Pedro Pablo Rubens pintaron una serie de cinco cuadros dedicados a los sentidos: La Vista, El Oído, El Olfato, El Tacto y El Gusto. Jan Brueghel pintó el escenario de cada cuadro y Pedro Pablo Rubens las figuras que encarnan a los sentidos. La serie fue creada para los archiduques Alberto de Austria e Isabel Clara Eugenia con el fin de decorar el Salón de Audiencias del palacio de Tervuren. Con posterioridad a la muerte del archiduque, la serie fue regalada al duque Wolfgang Wilhelm von Pfalz-Neuburg -aún se desconocen los motivos- y después fue obsequiada al cardenal infante Fernando. Pero para 1636 se encontraron instalados en el cuarto de lectura del rey Felipe IV, en el Real Alcázar de Madrid ${ }^{3}$.Este artículo se centrará en el análisis ${ }^{4}$ de $L a V_{i s t a}{ }^{5}$. Se puede empezar a observar el cuadro a partir de

1 Vicente Carducho, Diálogos de la pintura. Su defensa, origen, esencia, definición, modos y diferencias, ed. Francisco Calvo Serraller (Madrid: Ediciones Turner, 1979), 317. El tratado fue publicado en el año 1633.

2 Carducho, Diálogos de la pintura, 318.

3 Bárbara Welzel, "Los cuadros de los cinco sentidos de Jan Brueghel como espejo de la cultura de la corte de Alberto e Isabel Clara Eugenia", en El Arte en la Corte de los Archiduques Alberto de Austria e Isabel Clara Eugenia (1598-1633). Un reino imaginado, ed. Alejandro Vergara (Madrid: Museo del Prado, 2000), 8996.

4 Donald Preziosi señalaba, en un ensayo intitulado Art History: Making the Visible Legible, que uno de los objetivos principales de todo estudio histórico sobre arte consiste en hacer a las obras más legibles en el presente, esto es, se trata de ofrecer interpretaciones convincentes de un objeto, con la información histórica suficiente. Sobre la base de este planteamiento, el análisis de uno de los cinco cuadros de la serie de Los Sentidos, es fundamental para comprender la complejidad del problema de lo visual en la Historia del Arte, es decir, mediante el estudio del lenguaje solo de una imagen, es posible una aproximación a un horizonte cultural determinado y por ello, a diversas prácticas culturales del mismo - en la medida en que una pintura o bien, La Vista, puede ser considerado un documento- pues lo visual, de acuerdo con E.H. Gombrich, implica una forma de comunicar -junto con lo verbal-, de conocer y por lo tanto, de aprender. Donald Preziosi, "Art History: Making the Visible Legible", en The Art of Art History: A Critical Anthology, ed. Donald Preziosi (Nueva York: Oxford University Press, 2009), 7-8, 11. Ernst Hans Gombrich, La imagen y el ojo. Nuevos estudios sobre la psicología de la representación pictórica, trad. Alfonso López Lago y Remigio Gómez Diaz (Madrid: Alianza Editorial, 1987), 163,166. Asimismo, La Vista es una representación de la práctica cultural de la apreciación en el siglo XVII, uno de los tópicos sobre los que se reflexionará más delante. Miguel Morán Turina y Javier Portús Pérez, El arte de mirar. La pintura y su público en la España de Velázquez (Madrid: Ediciones ISTMO, 1997), 34.

5 Pedro Pablo Rubens y Jan Brueghel "El Viejo", La Vista, 1617, óleo sobre tabla, Museo Nacional del Prado, Madrid. "La Vista", Museo Nacional del Prado, consultado el 15 de diciembre de 2019, https://www. 
la figura femenina que representa al sentido de la vista -Venus, quien mira y se detiene a reflexionar sobre una imagen sostenida por el Amor-, en igual medida es necesario poner toda la atención en el lugar y ambiente que rodea a Venus. Es un espacio repleto de pinturas de autores como Rubens, Tiziano, Rafael, Snyders y Brueghel, bustos, esculturas y objetos relacionados con la ciencia ${ }^{6}$, todos ellos colocados unos encima de otros configurando una habitación desordenada y profunda, pero completamente ocupada y atiborrada de diferentes elementos.

Desde la izquierda superior hacia la derecha inferior de la composición -y siguiendo el orden en el que se distribuye la luz que entra través del arco, esto es, diagonalmente-, destacan un grupo de pinturas por su tamaño y saturación, en contraste con las que se ubican a la derecha y al fondo de la habitación. Además, a la izquierda a través del arco se advierte el palacio de Coudenberg, junto con jardines, fuentes y diversos animales. Es decir, el entorno es una muestra de la cultura cortesana ${ }^{7}$. Sin duda, la distribución del espacio, la luz y el color en La Vista, generan gran dinamismo en la imagen, es decir, Brueghel y Rubens pintaron una escena que el espectador podría mirar y volver a mirar, y en cada ocasión, encontrar un elemento nuevo donde detenerse a contemplar -de manera similar a Venus-. Así pues, la imagen es una invitación a la apreciación.

De acuerdo con Barbara Welzel, cuando La Vista fue colocado en una de las bibliotecas del Real Alcázar de Madrid, el cuadro funcionaba "como imagen de la soberanía española sobre los Países Bajos" ". Ahora bien, este edificio era el lugar desde donde se gobernaba España tenía una decoración basada principalmente en pinturas y "era representativo de una idea y de una imagen" del rey Felipe IV 9 .

En ese sentido, se puede pensar al espacio y a las imágenes como una forma de legitimar una figura de poder y una forma de gobierno. Así mismo, y de acuerdo con Georges Balandier, el poder estaría justificado no sólo de manera racional, sino con ayuda de imágenes y símbolos para construir una especie de propaganda $\neg$ para un público muy específico- ${ }^{10}$. Al mismo tiempo y conforme a lo planteado por Bronisław Baczko, este conjunto de imágenes y símbolos permite formar un imaginario ${ }^{11}$. En consecuencia,

museodelprado.es/coleccion/obra-de-arte/la-vista/494fd4d5-16d2-4857-811b-e0b2a0eb7fc7

6 Matías Diaz Padrón y Mercedes Royo- Villanova, David Teniers, Jan Brueghel y los gabinetes de pinturas (Madrid: Museo Nacional del Prado, 1992), 117.

$7 \quad$ Welzel, Los cuadros de los cinco sentidos de Jan Brueghel, 90.

$8 \quad$ Welzel, Los cuadros de los cinco sentidos de Jan Brueghel, 96.

$9 \quad$ Fernando Checa Cremades, "El Real Alcázar de Madrid”, en El Real Alcázar de Madrid. Dos siglos de arquitectura y coleccionismo en la corte de los Reyes de España, ed. Fernando Checa Cremades (Madrid: Museo del Prado-Ediciones Nerea-Comunidad de Madrid, 1994), 18.

10 De acuerdo con Georges Balandier, el poder como un sistema es creíble y aceptado en la medida en que exista, se conserve y legitime a través de imágenes y mediante la manipulación de símbolos. Asimismo, el poder puede preservarse con ayuda de la historia que es construida, reconstruida y/o interpretada a favor de las necesidades del poder actual. George Balandier, El poder en escenas. De la representación del poder al poder de la representación, trad. Manuel Delgado Ruiz (México: Ediciones Paidós, 1994), 16-19.

11 Por imaginario, de acuerdo con Bronisław Baczko, puede entenderse como el modo en que los 
es posible plantear la siguiente pregunta para la investigación: ¿cómo el cuadro La Vista de Jan Brueghel y Pedro Pablo Rubens contribuye en la consolidación de un imaginario cortesano?

Por consiguiente, el trabajo está divido de la siguiente manera: en primer lugar se, explicarán los elementos que conforman un imaginario cortesano. En segundo lugar, se expondrá la relación entre el escenario del cuadro y dicho imaginario cortesano, así como también el vínculo del lenguaje visual de la pintura con algunas ideas señaladas por Vicente Carducho en uno de los tratados de pintura más importantes del siglo XVII español: Diálogos de la pintura. Su defensa, origen, esencia, definición, modos y diferencias ${ }^{12}$.

Es necesario mencionar, que el tratado de Carducho, escrito en 1633, posee un valor testimonial fundamental para conocer a los principales coleccionistas de Madrid en la primera mitad del siglo XVII y además, constituye una fuente relevante para el conocimiento y estudio de la práctica del coleccionismo - que involucraba actividades tales como el comercio y el intercambio de obras de arte en el medio cortesano y la propia representación pictórica de miembros de la corte llevando a cabo dichas actividades-, y de la apreciación visual en la corte, las cuales evidentemente estaban vinculadas con los "aficionados al arte" y con sus posesiones ${ }^{13}$.

Asimismo, se identificarán algunos elementos de La Vista con las dos bibliotecas, o librerías, y el dormitorio del rey Felipe IV en el Real Alcázar de Madrid; se analizará el espacio en donde estuvo colocada la obra, es decir, el oeste del palacio del Real Alcázar y finalmente, se realizará una aproximación al tópico del coleccionismo en la primera mitad del siglo XVII.

hombres se construyen a sí mismos, es decir, la manera en la que se representan, se visualizan, se identifican y se proyectan hacia el pasado y el futuro y la forma con la que refuerzan el poder mediante la apropiación de símbolos. Bronisław Baczko, Los imaginarios sociales. Memorias y Esperanzas Colectivas, trad. Pablo Betesh (Buenos Aires: Ediciones Nueva Visión, 1999), 12-17.

12 Carducho, Diálogos de la pintura.

13 José Juan Pérez Preciado mencionaba en su ensayo dedicado a los Diálogos de la pintura de Vicente Carducho, que este tratado es una fuente importante para conocer diversas prácticas culturales y sociales en la corte durante los años del primer tercio del siglo XVII; además de ser un texto que describe los ambientes en los que se realizaba la práctica de la apreciación y finalmente, pero no menos importante, por ser un texto que discute sobre la teoría artística y la práctica pictórica. José Juan Pérez Preciado, "Art Aficionados at Court", en On Art and Painting. Vicente Carducho and Baroque Spain, ed. Jean Andrews, Jeremy Roe y Oliver Noble Wood (Cardiff: University of Wales Press, 2016), 119-121. Asimismo, Juan Luis González García, apuntaba que tanto el tratado de Vicente Carducho como el de Francisco Pacheco, -El arte de la pintura- ofrecen la clave para comprender los juicios críticos que elaboraban pintores y espectadores sobre la pintura y quiénes de ellos estaban más "capacitados" para dicha actividad, es decir, los Diálogos de la pintura y El arte de la pintura, son dos de los variados textos sobre teoría y práctica pictórica de la primera mitad del siglo XVII que posibilitan la comprensión de múltiples tópicos relacionados con la teoría artística. Juan Luis González García, “¿`Vencen al arte del decir'? Estilo, decoro y juicio crítico de los pintores- predicadores de los siglos XVI y XVII", en Sacar de la sombra lumbre. La teoría de la pintura en el Siglo de Oro (1560-1724), ed. José Riello (Madrid: Museo Nacional del Prado, 2012), 103. 


\section{Imaginario cortesano: el auge de las artes.}

De acuerdo con John Elliott y Jonathan Brown, durante los años que transcurrieron al final del siglo XVI y comienzos del XVII, España había sufrido una crisis política, pues se encontraba en guerra contra Holanda y Francia. Sin embargo, en este periodo la monarquía vivió un gran momento cultural debido a que las artes habían tenido un extraordinario crecimiento desde el punto de vista cuantitativo y cualitativo $^{14}$. La imagen de la soberanía de Felipe IV y el esplendor de su poder fueron algunos de los aspectos que mayor importancia tuvieron, no obstante, a través de una serie de ceremonias y rituales, que iban desde el acto de comer hasta las fiestas suntuosas, y las múltiples transformaciones, remodelaciones y redecoraciones de la mayoría de los palacios del rey, se pretendía legitimar y afirmar no sólo la grandeza del monarca, sino convertir la corte -entendida como un lugar propiamente, pero también, como el conjunto de "las personas asociadas con la presencia del rey"15 "en el centro de la vida artística y cultural de la Monarquía" "16 donde el rey debía ser el centro de atención, así pues tanto las ceremonias públicas como las producciones artísticas harían visible al monarca prácticamente en cualquier lugar ${ }^{17}$.

Las grandes inversiones en cuadros, arte o tesoros que podían realizar las clases privilegiadas ante la crisis económica hablaban de cómo la élite se preocupaba por mantener una idea y una identidad con el poder. Se trataba de conservar la imagen de un grupo muy delimitado que configuraba la jerarquía tradicional y que se desenvolvía en el espacio cortesano. "Las posesiones en forma de casas, muebles, pinturas o joyas, constituían simultáneamente símbolos visibles del rango social" 18 .

En igual medida, las remodelaciones de los edificios de la corte en un periodo de crisis económica, tenían la intención de crear una imagen opuesta y consolidar la fama del rey capaz de restablecer el poderío de un imperio, es decir, serían la imagen que preservara a lo largo del tiempo la grandeza y el valor de un monarca. En palabras de John Elliot y Brown y de acuerdo con las ideas prevalecientes: "los príncipes serían juzgados por sus edificios, y por ellos ensalzados o condenados" 19 . Por consiguiente, estos aspectos pueden comprenderse como una suerte de imaginario cuya característica principal, sería la solidez de todas las proyecciones pretendidas por este círculo

14 John Elliott y Jonathan Brown, Un palacio para el rey. El Buen Retiro y la Corte de Felipe IV (Madrid: Revista de Occidente- Alianza Editorial), 238.

15 Elliott y Brown, Un palacio para el rey. El Buen Retiro y la Corte de Felipe IV, 38.

16 Elliott y Brown, Un palacio para el rey. El Buen Retiro y la Corte de Felipe IV, 38-42, 238.

17 Verónica Salazar Baena, "El cuerpo del rey: poder y legitimación en la monarquía hispánica", Fronteras de la historia, julio-diciembre de 2017, pág. 153, https://revistas.icanh.gov.co/index.php/fh/article/view/109/85

18 Elliott y Brown, Un palacio para el rey. El Buen Retiro y la Corte de Felipe IV, 237.

19 Elliott y Brown, señalaban que esta élite, que poseía el tiempo y el dinero suficiente para gastar, también generaba oportunidades para que artistas y literatos encontraran protectores y público. Elliott y Brown, Un palacio para el rey. El Buen Retiro y la Corte de Felipe IV, 44, 239. 
social -basadas en sus experiencias, sus deseos y sus aspiraciones, ya sea a nivel individual o colectivo, pero que funcionaban para crear identidades ${ }^{20}-$, es decir, es posible llamar a esta confluencia de imágenes, ideas y acciones como imaginario cortesano.

\section{La habitación y el cuadro: escenarios de lo sensorial y de lo simbólico}

De acuerdo con Diaz Padrón y Royo-Villanova, La Vista es una pintura de gabinete, un género que se desarrolló entre los siglos XVI y XVII, pues representa de manera minuciosa y detallada una habitación con cuadros, esculturas, tapices y otros objetos curiosos $^{21}$. A la izquierda al fondo a través de la ventana se puede observar el palacio de Bruselas, lo que permite pensar que la habitación pintada es territorio de los archiduques Alberto de Austria e Isabel Clara Eugenia, sin embargo, en el pasillo de lado derecho del cuadro, la luz que desintegra poco a poco los objetos genera un juego en el que se pierde la precisión de esas piezas ${ }^{22}$, y en consecuencia, es posible pensar que se trata de una obra que expone lo aparentemente real pero que al mismo tiempo, desafía al espectador a través de elementos imaginarios ${ }^{23}$.

Las reducciones hechas por Brueghel exponen diferentes significados del sentido de la vista, es decir, algunas pinturas como la que observa Venus, La Curación del ciego, o la pintura Santa Cecilia ubicada casi en el centro de la sala, hacen referencia a la recuperación de la vista de manera sensorial y espiritual, mientras que el doble retrato de los archiduques, el retrato ecuestre de Alberto y el águila bicéfala de los Habsburgo, se convierten en una invitación para que se observe todo lo que les pertenece a ambos miembros de la corte ${ }^{24}$. De tal manera, Brueghel logró ofrecer al espectador una muestra del mundo cortesano a través del exterior, es decir, mediante la abertura en la pared o arco, es posible observar el paisaje, así, la obra es el retrato del medio en el que se desenvolvían los archiduques ${ }^{25}$.

La Vista es una obra completamente dinámica, es decir, cada cuadro representado en la imagen puede ser considerado, incluso, como un plano de la pintura, lo que en consecuencia, ofrece un espacio tan profundo que es completado y rellenado por diversos objetos, esculturas y pinturas. Asimismo, en el interior y en la parte inferior de la habitación se pueden observar pinturas encimadas unas con otras, fuertemente saturadas, lo que constituye una muestra del énfasis realizado por los artistas para destacar el valor de la pintura. Es decir, el lado derecho de la imagen está sumamente cargado con cuadros - unos más pigmentados que otros- lo que posibilita afirmar que

20 Baczko, Los Imaginarios sociales, 27-30.

21 Diaz Padrón y Royo-Villanova, David Teniers, Jan Brueghel, 25.

22 Diaz Padrón y Royo- Villanova, David Teniers, Jan Brueghel, 115.

23 Julián Gállego, El cuadro dentro del cuadro (Madrid: Ediciones Cátedra, 1978), 140.

24 Diaz Padrón y Royo- Villanova, David Teniers, Jan Brueghel, 114, 116, 121.

25 Gállego, El cuadro dentro del cuadro, 87. 
Brueghel está defendiendo, al igual que Carducho, el arte de la pintura. Dicho de otro modo, es una obra que exalta a la pintura y resalta a los objetos y paisajes retratados, es por ello, que los pintores fueron capaces de otorgar a su dueño "en una sola obra, una colección entera, aunque fuera solo en imagen" 26.

En igual medida, la pared central de la habitación fragmenta la representación del palacio de Bruselas con sus jardines, pero no es una ruptura gratuita, en realidad, Brueghel lo que hace es una invitación para observar, en primer lugar, lo que está dentro de la habitación, y en segundo lugar, pero no menos importante, todo lo que el exterior puede ofrecer al espectador, es decir, el paisaje es un recorrido profundo en el territorio de la corte, acentuado por los gradientes de luz del cuadro. Desde el punto de vista del imaginario cortesano, lo externo a la habitación es lo que la colectividad le otorga a una figura de poder, esto es, una serie de representaciones que rodea a dicha figura, para con ellas ordenar y jerarquizar lo social, mientras que el espacio interno de La Vista, puede ser considerado una representación del poder individual, pero manifestado en diversos objetos de la cultura ${ }^{27}$.

Para 1636 -año en el que el cuadro ya pertenecía al rey Felipe IV-, en las librerías del monarca en el Alcázar, los globos terráqueos y los libros que se encontraron ahí para los momentos de descanso del rey, explicaban las preocupaciones del monarca por conocer lo fundamental para gobernar el Imperio. Eran libros traducidos al castellano, italiano y francés, especializados en historia, poetas griegos y latinos, geografía, medicina, botánica, artillería, entre otras materias ${ }^{28}$. Aunado a esto, en el dormitorio del rey se encontraban los retratos de algunos miembros de su familia ${ }^{29}$.

Así pues, dentro de estas habitaciones se concentró lo que Baczko explica como los símbolos o formas simbólicas - que pueden ser religiosas, políticas, económicas, etc., donde se articulan una serie de imágenes, ideas y acciones-, o bien, la base de los imaginarios, pues mediante la relación establecida entre estos signos y el monarca, probablemente se adquirían los valores y conductas que favorecían la legitimación de su poder ${ }^{30}$. Por ejemplo, las posiciones en las que se encuentran Venus y el Amor son una incitación para que el espectador se acerque a observar de la misma manera en que las dos figuras observan, esto es, con mucho detalle y detenidamente, lo que puede interpretarse como una invitación para reflexionar sobre la pintura. Es decir, el escenario de La Vista y las habitaciones del rey Felipe IV, así como las actitudes que

\footnotetext{
26 Diaz Padrón y Royo- Villanova, David Teniers, Jan Brueghel, 23.

27 Baczko, Los Imaginarios sociales, 27.

28 Elena Santiago Páez, "Las bibliotecas del Alcázar en tiempos de los Austrias”, en El Real Alcázar de Madrid. Dos siglos de arquitectura y coleccionismo en la corte de los Reyes de España, ed. Fernando Checa (Madrid: Museo Nacional del Prado-Ediciones Nerea, 1994), 331.

29 Checa, "El Apartamento Bajo de Verano y las Bóvedas de Tiziano”, en El Real Alcázar de Madrid. Dos siglos de arquitectura y coleccionismo en la corte de los Reyes de España, ed. Fernando Checa (Madrid: Museo Nacional del Prado-Ediciones Nerea, 1994), 406.

30 Baczko, Los imaginarios sociales, 29.
} 
representa la imagen, son espacios y acciones donde lo simbólico trabaja para justificar el poder del monarca, como una invitación para continuar con la práctica de la valoración y apreciación visual.

Asimismo, en el cuadro se observa al centro de la sala, sobre repisas, algunos bustos y cabezas escultóricas y para 1636, las únicas esculturas en el Real Alcázar de Madrid, se encontraban en el Jardín de los Emperadores y en el pasillo que conducía a él. Además de estas, las únicas habitaciones que contaban con esculturas, como parte de la decoración, eran las bibliotecas del rey Felipe IV, pues en estas se hallaban "emperadores pequeños de medio cuerpo arriba"31.

Tiempo después, con las remodelaciones a cargo de Diego Velázquez, la escultura fue considerada como un elemento importante para adornar los muros en el interior del palacio madrileño. En este sentido, es posible pensar que La Vista, al ser una representación de una colección tan completa, inspirara al monarca a valorar este tipo de piezas, pues para los años cuarenta del siglo XVII, Velázquez había sido enviado por Felipe IV a Italia a buscar estatuas míticas de la antigüedad, con la intención de comenzar un "museo imaginario" 32 .

\section{Fascinación y deleite: funciones de La Vista}

Deleitarse y fascinarse ante lo que se observa es una de las funciones del sentido de la vista y el cuadro de Rubens y Jan Brueghel es un símbolo de este estado de admiración. En la pintura, la figura de Venus y el Amor se encuentran rodeados de cuadros, de flores, de esculturas hechas por Miguel Ángel, de retratos, de astrolabios, lupas, globos terráqueos, telescopios, escalímetros, etc. Es decir, el escenario es una representación de todo lo que la vista puede abarcar por si sola y con ayuda de otros instrumentos que permiten al hombre una mejor comprensión de la naturaleza por medio del $\mathrm{ojo}^{33}$.

Además, es una "defensa de la supremacía de la pintura como arte de la visión, frente a los otros sentidos" ${ }^{34}$. Vicente Carducho señalaba que a partir de la vista el pintor comenzaba un proceso de creación: "los sugetos que ai entre los hombres, y como cada uno aspira a imitar, o reengendrar su semejanza y la pintura es parto del enten-

31 Miguel Morán Turina, "Las estatuas del Alcázar. Notas sobre las colecciones escultóricas de los Austrias", en El Real Alcázar de Madrid. Dos siglos de arquitectura y coleccionismo en la corte de los Reyes de España, ed. Fernando Checa (Madrid: Museo Nacional del Prado-Ediciones Nerea, 1994), 251.

32 Morán Turina, "Las estatuas del Alcázar”, 254-255.

33 Diaz Padrón y Royo- Villanova, David Teniers, Jan Brueghel, 116.

34 Welzel, "Los cuadros de los cinco sentidos de Jan Brueghel”, 97. Uno de los argumentos de los teóricos de la pintura del siglo XVII, en defensa de la pintura como arte liberal, se refiere al de la actividad intelectual relacionada con la práctica pictórica, lo que traía como consecuencia, de acuerdo con Pérez Preciado, que personas con un estado social alto, decidieran coleccionar pinturas y exhibirlas. Pérez Preciado, "Art Aficionados at Court", 119. 
dimiento que concibo con los sentidos" ${ }^{35}$. Pero además, el autor de los Diálogos de la pintura, reconocía el impacto que la pintura podía provocar a aquel que la observara: "Que las pinturas ayan movido a respeto, a ira, a piedad, a devoción, a lágrimas, y a temor, es cosa tan sabida"36.

En consecuencia, se puede apreciar el poder que una imagen podía alcanzar, en este caso, La Vista puede considerarse como una representación con la capacidad de convencer al espectador -el primero de los observadores sería el rey, quien había escogido objetos de tamaño pequeño pero muy particulares para sus bibliotecas $-^{37}$, de la necesidad de "existir en primer lugar por la imagen" 38 , y de la de proyectarse hacia el pasado y el futuro ${ }^{39}$, o bien, de materializar lo que la imagen representaba. La serie de Los sentidos se ubicaba en una de las habitaciones más agradables del palacio madrileño y aunque las paredes de este lugar estaban totalmente cubiertas de pinturas ${ }^{40}$, los cinco cuadros de Brueghel y Rubens, estaban colocados a una distancia corta para ser contemplados por Felipe $\mathrm{IV}^{41}$. Carducho exponía la importancia de pintar considerando la distancia entre la obra y el público, pues la pintura debía cumplir con su función moral y política: "se debe pintar una cosa que se ha de ver a quatro pies de distancia"42.

Aunado a esto, Carducho distinguía la relación del sentido de la vista con la labor del pintor y con el espacio que era decorado con obras de arte y como resultado, señalaba que una habitación vacía y sin decoración no tenía utilidad: "que es ver una grande galería o quadra de paredes desiertas, sin cosa en que detener la vista" ${ }^{43}$. Es por ello que el cuadro de Brueghel y Rubens adquiría una mayor significación dentro del espacio, se trataba de una representación que apuntaba a la necesidad de obtener más y más obras de arte con la función de que estas fuesen observadas, para deleitar al público y para darle una connotación más importante a la práctica del coleccionismo y a la de la apreciación visual, dos acciones que formaban parte del ritual de legitimación del poder.

En el siglo XVI y en los primeros años del XVII, las reflexiones y la preparación intelectual- artística por parte de los miembros de la aristocracia fueron dos de las actividades que se desarrollaron en el seno de las colecciones, sin embargo, durante el reinado de Felipe IV, estas actitudes se extendieron y se fortalecieron en la corte de Madrid, al grado de ser reconocidas por otros reinos. La afición por la pintura en estos

35 Carducho, Diálogos de la pintura, 273

36 Carducho, Diálogos de la pintura, 309.

37 Santiago Páez, "Las bibliotecas del Alcázar", 328.

38 Balandier, El poder en escenas, 13.

39 Baczko, Los imaginarios sociales, 15.

$40 \quad$ Santiago Páez, "Las bibliotecas del Alcázar",332.

41 Welzel, Los cuadros de los cinco sentidos de Jan Brueghel, 96.

42 Carducho, Diálogos de la pintura, 263.

43 Carducho, Diálogos de la pintura, 321. 
años se extendió y costumbres como la de mostrar la casa o visitar a otros solo para observar y alabar las colecciones, adquirió gran importancia ${ }^{44}$.

\section{Un símbolo de grandeza de la corte española.}

Uno de los edificios del rey que resaltaba por su arquitectura y por sus colecciones artísticas era el Real Alcázar de Madrid y puede considerarse como una de las imágenes que hablaban sobre el poder del rey. El Alcázar fue un edificio que constantemente tuvo remodelaciones desde el siglo XV hasta el incendio de 1734. Las transformaciones se daban con base en los gustos de los reyes, quienes decidían cómo cambiar las habitaciones y las nuevas funciones que estas tendrían ${ }^{45}$. De acuerdo con Fernando Checa Cremades, el atractivo del palacio estaba precisamente en la conservación del pasado, es decir, se encontraban dentro de él, pinturas de todos los géneros, esculturas, tapices, libros y manuscritos de todos los tiempos, que eran reflejo del poder y de las acciones heroicas del rey ${ }^{46}$.

Ahora bien, ¿de qué manera se relaciona esta perspectiva a grandes rasgos del Alcázar con el cuadro de Jan Brueghel y Pablo Rubens? Resulta importante conocer y describir el espacio en el que se hallaba La Vista, en tanto que las similitudes entre el escenario del cuadro con la vida "real" de Felipe IV son muchas. Si bien, en la corte de Alberto e Isabel Clara Eugenia, esta pintura era reconocida y apreciada por su belleza, también lo fue por su utilidad para exponer la identidad política de los archiduques ${ }^{47}$, en palabras de Barbara Welzel, la pintura de Brueghel y Rubens era un "espejo de la cultura cortesana de Isabel Clara Eugenia y Alberto de Austria" 48 , mientras se encontraba en el palacio de Tervuren. En un segundo momento, en el espacio propio de Felipe IV, funcionaban como una imagen que representaba la soberanía del rey sobre los Países Bajos $^{49}$, esto significa que cuando el cuadro se ubicó en función de la biblioteca del rey, entonces, podía formar parte de otra serie de símbolos que creaban una determinada imaginación política y social que también legitimaban la imagen de poder del rey ${ }^{50}$.

Durante su reinado, Felipe II ordenó que se cambiara la decoración y la arquitectura del Real Alcázar. Una de las construcciones más importantes fue la de la

$44 \quad$ Morán Turina y Javier Portús, El arte de mirar, 35, 43.

45 Santiago Páez, "Las bibliotecas del Alcázar", 320.

46 Checa, "El Real Alcázar de Madrid", 18.

47 Alejandro Vergara, "La pintura en el ámbito de los archiduques", en El Arte en la Corte de los Archiduques Alberto de Austria e Isabel Clara Eugenia (1598-1633). Un reino imaginado, ed. Alejandro Vergara (Madrid: Museo del Prado, 2000), 64.

$48 \quad$ Welzel, Los cuadros de los cinco sentidos de Jan Brueghel, 83.

$49 \quad$ Welzel, Los cuadros de los cinco sentidos de Jan Brueghel, 96.

50 Bronisław Baczko explicaba que la asociación entre imaginación y política, es una parte fundamental para la construcción de figuras de poder, en tanto que esas figuras son aceptadas y apreciadas más allá de la fuerza y capacidad que representan, es decir, son admitidos "en función de la imaginación política y social que se les otorga o niega". Baczko, Los Imaginarios sociales, 11. 
Torre Dorada (II), Torre Alta o Torre Nueva que se ubicó en la esquina suroeste del Alcázar ${ }^{51}$. El interior de esta librería en tiempos de Felipe IV se caracterizaba por la decoración con objetos de tamaño pequeño, entre las que destacaban pinturas, esculturas de plata y bronce colocadas sobre repisas, relojes, estanterías con libros, así como globos terráqueos y muebles de ébano. Cada objeto y pintura de las bibliotecas era escogido cuidadosamente para el monarca ${ }^{52}$.

En 1633 Vicente Carducho describía en sus Diálogos de la pintura, algunas de las transformaciones que había tenido el palacio de Madrid $^{53}$, y señalaba que la Torre Dorada II era una de las mejores habitaciones del palacio: "En la misma torre encima desta pieza ai otra que corresponde a su grandeza en fabrica, y adorno de pinturas, estuques y dorado, donde su Magestad tiene una librería y están los libros enquadernados curiosa y uniformemente en estantes dorados, en correspondencia a la hermosura de la pieza. Están divididas en materias, y historias, y diferentes Facultades, para cuya inteligencia entre los adornos desta pieza ai dos globos, celeste, y terrestre, de mucha estima. Tiene la más deleitosa vista, que alcanza la ribera del rio Manzanares" 54 .

Ahora bien, en 1626 Juan Gómez de Mora, el arquitecto del rey, ubicó a la primer Torre Dorada o Torre de Francia en la esquina noroeste del edificio. Este cuarto era descrito como el otro lugar donde el rey Felipe IV guardaba sus libros y era una estancia de carácter privado ${ }^{55}$. De acuerdo con Elena Santiago, esta librería se decoró y adaptó a la manera de un studiolo ${ }^{56}$. Además, era una habitación que estaba repleta de cuadros, incluida la serie de Los Sentidos y desde la que se podían observar los jardines del palacio.

En este sentido, parece que existían dos librerías para el monarca y eran "las mejores habitaciones de cada ala del palacio" ${ }^{57}$. Entre esas dos bibliotecas se encon-

51 Santiago Páez, "Las bibliotecas del Alcázar", 319-320.

52 Santiago Páez, "Las bibliotecas del Alcázar", 328-330.

53 En el diálogo octavo, el maestro y el discípulo platican sobre la costumbre visitar las casas de la corte y de mostrar las pinturas y objetos preciosos que se tienen. El maestro comentaba al alumno, de las grandes pinturas que estaban guardadas en el palacio del Alcázar y del recorrido en el que le "enseñaron todas las que avia" y donde reconoció "lo mucho que ha ampliado el Alcázar con las obras que en él se han hecho". Carducho, Diálogos de la pintura, 427.

$54 \quad$ Carducho, Diálogos de la pintura, 432-433.

55 Santiago Páez, "Las bibliotecas del Alcázar", 324-326.

56 La doctora Elena Santiago explicaba que la Torre Dorada había sido redecorada con Felipe II, pero con Felipe IV, la habitación había adquirido el estilo del studiolo italiano, cuya función radicaba en ser el centro de estudio del rey, así como en conservar documentos y posteriormente colecciones y objetos raros. Santiago Páez, "Las bibliotecas del Alcázar", 320.

$57 \quad$ Elena Santiago expuso tres hipótesis sobre la existencia de las bibliotecas del rey Felipe IV. La primera señalaba que la biblioteca más antigua había desaparecido y por consiguiente, solo quedó una para el monarca. La segunda, decía que ambas bibliotecas coexistieron y la tercera apuntaba a que los libros de una torre, habían sido llevados a la otra torre. No obstante, la doctora menciona a la primera y a la segunda como las más verosímiles, en tanto que la información de los inventarios correspondía con las otras fuentes literarias, con los planos y con el tratado de Vicente Carducho. Santiago Páez, "Las bibliotecas del Alcázar”, 325, 334. 
traban, hacia el sur, el 'cubillo de las trazas' que era un cuarto de carácter privado donde se guardaban documentos que hacían referencia a la participación pública de la familia real. Posterior al salón de las trazas estaba el Guardajoyas, estancia donde se encontraban los objetos curiosos y preciosos. También se conservaban en este lugar pinturas, muebles y demás objetos traídos de muchas partes.

Así pues, un área del ala oeste del Real Alcázar de Madrid fue concebida como parte del escenario de poder de Felipe IV, a través de los paisajes, de los muebles, de los libros, de los objetos preciosos, de los cuadros y esculturas que fueron elementos del imaginario cortesano, surge una relación con el escenario de La Vista y con una de las funciones de este sentido. En la descripción que Carducho realizaba del edifico, exponía la impresión que este le provocaba: "En una ausencia de su Magestad me enseñaron todas las que avia, y reconocí lo mucho que se ha ampliado este Alcazar con las obras que en el se han hecho. Admirome la fábrica, por estar compuesta de aposentos baxos, y escuros, que estaban inhabitables, y agora es una agradable habitación (tanta fuerza tiene el poder, y el Arte) con que han escusado los Reyes el salir de la Corte los Veranos" $" 58$.

\section{La Vista: una representación del coleccionismo}

La Vista es considerada la obra más representativa de la serie de Los Sentidos y fue modelo de imitación durante el siglo XVII ${ }^{59}$. De acuerdo con Díaz Padrón y Mercedes Royo, Ertz señaló que había una clara identificación entre las escenas de la serie con los archiduques Alberto de Austria e Isabel Clara Eugenia. Específicamente en La Vista se advierte al fondo con la representación del palacio de Bruselas y con el doble retrato de los archiduques sobre la mesa. La serie de objetos, cuadros, esculturas y flores, que se encuentran retratados en el cuadro de Jan Brueghel y Rubens, fueron realizados gracias al acceso que tenía Brueghel a las colecciones reales ${ }^{60}$. Y aunque autores como Hymans ${ }^{61}$ o Rooses ${ }^{62}$, según Díaz Padrón, hayan rechazado la tesis de Ertz sobre la vinculación de los gabinetes con los archiduques, destaca el hecho de que es una representación de una práctica cultural arraigada en Europa en el siglo XVII: el coleccionismo.

Esta práctica, estaba caracterizada en primer lugar, por un cambio de actitud frente a una imagen, es decir, los dueños de las colecciones, no sólo las valoraban

$58 \quad$ Carducho, Diálogos de la pintura, 427.

59 Diaz Padrón y Royo- Villanova, David Teniers, Jan Brueghel, 114.

60 Diaz Padrón y Royo- Villanova, David Teniers, Jan Brueghel, 114.

61 Hymans consideraba que las pinturas retratadas por Brueghel en la serie de Los Sentidos, no pertenecían a la colección de los archiduques, sino que se trataba de las obras que estaban en casa del pintor. Diaz Padrón y Royo- Villanova, David Teniers, Jan Brueghel, 114.

62 Rooses señalaba que la elaboración de la serie de Los Sentidos sólo era un pretexto de Brueghel para presentar la colección de los archiduques. Diaz Padrón y Royo- Villanova, David Teniers, Jan Brueghel, 114. 
y las apreciaban, sino que podían reflexionar sobre ellas, esto es, había una preparación intelectual mayor y diferente a la del siglo $\mathrm{XVI}^{63}$. En segundo lugar, el coleccionismo era fundamental para el prestigio de la corte y era un impulso para los artistas quienes viajaban para conocer y explorar otro tipo de pinturas ${ }^{64}$. Finalmente, el coleccionismo se relacionaba ampliamente con el mecenazgo y con los nuevos problemas que esto implicaba, es decir, las formas en las que se comprendían las relaciones entre un mecenas y un artista y la manera en la que un cuadro adquiría el sentido de una inversión económica ${ }^{65}$.

Jonathan Brown explicó que a finales del siglo XVI la pintura ocupaba un lugar inferior en comparación con las llamadas "cámaras de maravillas", espacios donde se guardaban los objetos maravillosos del mundo natural y artificial, así como también aquellos considerados "raros" que en su mayoría eran costosos y de no fácil acceso a cualquier persona. Los cuadros estaban dentro de estas cámaras, pero no se comparaban con la cantidad de objetos de oro y plata que los rodeaban. Sin embargo, después del año 1600 la pintura comenzó a ser revalorada en el medio cortesano ${ }^{66}$.

Vicente Carducho en sus Diálogos de la pintura hablaba de la apreciación que la pintura poco a poco había ganado: "Estas mismas ciencias (la Medicina, las letras y la filosofía) están oi en tan grande estimación: con justa causa podrá la Pintura alentar sus esperanzas con exemplos tales, y por lo menos la han de favorecer los doctos, y bien entendidos. Y espero en su propio valor (pirámide legal y constante) que se ha de ver en esta Monarquía con el aprecio y estimación que se le debe" ${ }^{67}$.

Uno de los coleccionistas más importantes fue el rey Felipe IV, quien había heredado la colección de su familia y tenía bajo su dominio aproximadamente dos mil cuadros. Posteriormente, con las múltiples transformaciones de sus palacios, compró más pinturas para decorar los muros. Además, con el paso del tiempo el rey adquirió obras de los mejores pintores del siglo XVI y XVII, sobre todo italianos y flamencos ${ }^{68}$. Como lo señaló Checa Cremades, en los años treinta "Rubens, dispuesto por la sabia mano de Velázquez, centra la atención estética de un Felipe IV cada vez más deseoso de reflejar en su colección una determinada imagen de su poderío político"69.

En este sentido, es posible apreciar cómo Felipe IV a través de la manipulación de una serie de imágenes y mediante la práctica del coleccionismo, junto con la

63 Morán Turina y Javier Portús, El arte de mirar, 35.

64 Fernando Checa Cremades y Miguel Morán Turina, "El fin del coleccionismo ecléctico y el nuevo papel del mecenas", en El Barroco (Madrid: Ediciones Istmo, 1989), 63.

65 Checa Cremades y Miguel Morán, "El fin del coleccionismo ecléctico", 59.

66 Jonathan Brown, “Nos quedamos atónitos ante la cantidad de pinturas' El coleccionismo regio en el siglo XVII", en El Real Alcázar de Madrid. Dos siglos de arquitectura y coleccionismo en la corte de los Reyes de España, ed. Fernando Checa (Madrid: Museo Nacional del Prado-Ediciones Nerea, 1994), 449-450.

67 Carducho, Diálogos de la pintura, 443.

68 Brown, "Nos quedamos atónitos ante la cantidad de pinturas'”, 451.

69 Checa, "El Real Alcázar de Madrid”, 22. 
de la valoración y apreciación visual, legitimaba su poder y su propia imagen como gobernante de España, es decir, a través de los cambios y decoraciones del espacio, el rey comenzaba a crear un nuevo mundo, donde la jerarquización era un elemento indispensable. Se trataba pues, de apropiarse de una serie de símbolos, tradiciones e incluso del pasado inmediato para hacer expresa su posición dentro de esa jerarquía y su derecho como la máxima figura de poder dentro de la corte ${ }^{70}$.

El pintor Vicente Carducho, reconocía esta función de las pinturas, pues además de ser el medio con el cual podían imitar a la naturaleza, a través de estas imágenes era posible: "perpetuar lo que el tiempo y el olvido consumen, y hazernos presente todos los casos, y las cosas pasadas, y por venir, y las ausentes, para que causen los mismos efectos, que aquellas cosas, y aquellos casos causaran o pudieran causar, quando real $\mathrm{y}$ verdaderamente estuvieran presentes" ${ }^{\prime \prime 1}$.

\section{Conclusiones}

El cuadro La Vista es un claro ejemplo sobre cómo puede representarse una idea de poder, pero también, es una obra que se materializa, es decir, representa diversas prácticas culturales y al mismo tiempo es parte central de dichas prácticas. En consecuencia, legitima la imagen del rey y, al mismo tiempo, forma parte de un imaginario.

El cuadro La Vista participaba en un tipo de coleccionismo que se desarrollaba en función de los intereses de la corona; era parte de una serie de nuevas actitudes en la primera mitad del siglo XVII y era una imagen -aunque "privada"-, con un fuerte uso político y un objeto con valor técnico y económico. Es decir, era un "desplazamiento de la imaginación en el campo discursivo" "72. Esta asociación entre imaginario y poder consistía en el reforzamiento y multiplicación del poder mediante la apropiación de símbolos. Así, La Vista, junto con los edificios del rey y su amplia colección, puede ser considerada como un emblema que formaba parte de una serie de representaciones colectivas, cortesanas, con múltiples funciones ${ }^{73}$.

En segundo lugar, la obra de Jan Brueghel y Rubens respondía a una necesidad de su presente, pues ante la crisis política y económica, la imagen de dominio y de poder del rey no podía fracturarse, por el contrario, requería adquirir firmeza. Debido a esto, los lugares donde habitaba Felipe IV, así como las ceremonias y rituales que se llevaban a cabo en esos espacios y las obras y objetos con que se decoraban las ha-

70 Balandier explicaba que "el pasado colectivo, elaborado en el marco de una tradición o de una costumbre, se convierte en fuente de legitimidad. Constituye entonces una reserva de imágenes, de símbolos, de modelos de acción; permite emplear una historia idealizada, construida y reconstruida según las necesidades y al servicio del poder actual. Un poder que administra y garantiza sus privilegios mediante la puesta en escena de una herencia". Balandier, El poder en escenas, 19.

71 Carducho, Diálogos de la pintura, 304.

72 Baczko, Los Imaginarios sociales, 11.

73 Baczko, Los Imaginarios sociales, 17. 
bitaciones tenían que hacer y convencer a los espectadores -incluido el propio Felipe IV-, sobre este concepto del rey.

Asimismo, el escenario del cuadro La Vista y las habitaciones del ala oeste del Real Alcázar de Madrid son dos espacios cargados de simbolismo que tenían mucha relevancia para la conservación del poder, en tanto que todo poder necesita rodearse de representaciones simbólicas ${ }^{74}$. Incluso podría pensarse, que la obra de Brueghel y Rubens guiaba la conducta del rey y le permitía construir su identidad como máximo gobernante de España.

Es preciso destacar que los diálogos sexto y octavo del tratado de pintura de Vicente Carducho, además de señalar cómo se debe pintar, en qué consiste este arte y qué materiales son los adecuados para trabajar, son una fuente que permite realizar reflexiones sobre cómo la práctica artística de la apreciación de la pintura, se conecta con otras prácticas culturales, sociales y económicas, como el coleccionismo. En otras palabras, es una obra que describe los ambientes sociales, económicos, intelectuales y artísticos de un sector durante la primera mitad del siglo XVII.

Finalmente, la problematización del cuadro La Vista a través del lenguaje visual permite un acercamiento a la realidad en la que fue elaborada dicha obra, es decir, observar a fondo para reflexionar y estudiar la riqueza de este periodo, sirve para comprender la complejidad de España durante la primera mitad del siglo XVII retratada por sus artistas.

\section{Bibliografía}

Baczko, Bronisław. Los imaginarios sociales. Memorias y Esperanzas Colectivas. Traducido por Pablo Betesh. Buenos Aires: Ediciones Nueva Visión, 1999.

Balandier, Georges. El poder en escenas. De la representación del poder al poder de la representación. Traducido por Manuel Delgado Ruiz. México: Ediciones Paidós, 1994.

Brown, Jonathan. “'Nos quedamos atónitos ante la cantidad de pinturas` El coleccionismo regio en el siglo XVII". En El Real Alcázar de Madrid. Dos siglos de arquitectura y coleccionismo en la corte de los Reyes de España, editado por Fernando Checa, 448-459. Madrid: Museo Nacional del Prado-Ediciones Nerea, 1994.

Carducho, Vicente. Diálogos de la pintura. Su defensa, origen, esencia, definición, modos y diferencias, editado por Francisco Calvo Serraller. Madrid: Ediciones Turner, 1979. 
Checa Cremades, Fernando. "El Real Alcázar de Madrid". En El Real Alcázar de Madrid. Dos siglos de arquitectura y coleccionismo en la corte de los Reyes de España, editado por Fernando Checa, 16- 42. Madrid: Museo Nacional del Prado-Ediciones Nerea, 1994.

. "El apartamento Bajo de Verano y las Bóvedas de Tiziano". En El Real Alcázar de Madrid. Dos siglos de arquitectura y coleccionismo en la corte de los Reyes de España, editado por Fernando Checa, 405-407. Madrid: Museo Nacional del Prado-Ediciones Nerea, 1994.

y Miguel Morán Turina. "El fin del coleccionismo ecléctico y el nuevo papel del mecenas”. En El Barroco, 59-65. Madrid: Ediciones Istmo, 1989.

Diaz Padrón, Matías y Mercedes Royo- Villanova. David Teniers, Jan Brueghel y los gabinetes de pinturas. Madrid: Museo Nacional del Prado, 1992.

Elliott, John y Jonathan Brown. Un palacio para el rey. El Buen Retiro y la Corte de Felipe IV. Madrid: Revista de Occidente- Alianza Editorial, 1981.

Gállego, Julián. El cuadro dentro del cuadro. Madrid: Ediciones Cátedra, 1978.

Gombrich, Ernst Hans. La imagen y el ojo. Nuevos estudios sobre la psicología de la representación pictórica, traducido por Alfonso López Lago y Remigio Gómez Diaz. Madrid: Alianza Editorial, 1987.

González García, Juan Luis. “ ¿'Vencen al arte del decir’? Estilo, decoro y juicio crítico de los pintores- predicadores de los siglos XVI y XVII". En Sacar de la sombra lumbre. La teoría de la pintura en el Siglo de Oro (1560-1724), editado por José Riello, 87-104. Madrid: Museo Nacional del Prado, 2012.

Morán Turina, Miguel. "Las estatuas del Alcázar. Notas sobre las colecciones escultóricas de los Austrias”. En El Real Alcázar de Madrid. Dos siglos de arquitectura y coleccionismo en la corte de los Reyes de España, editado por Fernando Checa, 248-263. Madrid: Museo Nacional del Prado-Ediciones Nerea, 1994.

y Javier Portús Pérez. El arte de mirar. La pintura y su público en la España de Velázquez. Madrid: Ediciones ISTMO, 1997.

Pérez Preciado, José Juan. “Art Aficionados at Court”. En On Art and Painting. Vicente Craducho and Baroque Spain, editado por Jean Andrews, Jeremy Roe y 
Oliver Noble Wood, 119-147. Cardiff: University of Wales Press, 2016.

Preziosi, Donald. "Art History: Making the Visible Legible". En The Art of Art History: A Critical Anthology, editado por Donald Preziosi, 7-11. Nueva York: Oxford University Press, 2009.

Salazar Baena, Verónica. "El cuerpo del rey: poder y legitimación en la monarquía hispánica". Fronteras de la historia, julio-diciembre de 2017. https://revistas.icanh.gov.co/index.php/fh/article/view/109/85 https://doi. org/10.22380/20274688.109

Santiago Páez, Elena. "Las bibliotecas del Alcázar en tiempos de los Austrias". En El Real Alcázar de Madrid. Dos siglos de arquitectura y coleccionismo en la corte de los Reyes de España, editado por Fernando Checa, 318-343. Madrid: Museo Nacional del Prado-Ediciones Nerea, 1994.

Vergara, Alejandro. "La pintura en el ámbito de los archiduques". En El Arte en la Corte de los Archiduques Alberto de Austria e Isabel Clara Eugenia (15981633). Un reino imaginado, editado por Alejandro Vergara, 64-81. Madrid: Museo del Prado, 2000.

Welzel, Bárbara. "Los cuadros de los cinco sentidos de Jan Brueghel como espejo de la cultura de la corte de Alberto e Isabel Clara Eugenia". En El Arte en la Corte de los Archiduques Alberto de Austria e Isabel Clara Eugenia (1598-1633). Un reino imaginado, editado por Alejandro Vergara, 82-98. Madrid: Museo del Prado, 2000. 